\title{
PENGARUH SENAM NIFAS TERHADAP KECEPATAN INVOLUSI UTERI IBU POST PARTUM DI DESA GEDANGAN GROGOL SUKOHARJO
}

\author{
Oleh : \\ Ratna Indriati ${ }^{1}$ Tunjung Sri Yulianti ${ }^{2}$ Ika Fitriani Mulyanto ${ }^{3}$
}

\begin{abstract}
The Background of One of a physiological changes during the puerperium is involution uteri begin immediately after birth.Involution uteri is the clinical very important, because it ' $s$ a possibility that the process could be disrupted bleeding parturition. Involution uteri to speed up the process, one who advocated is gymnastic exercise performed after parturition the body feel better again.However, not all the mother after partus performing gymnastic parturition with regularly every day.Based on the observation of the post partum in the village of Gedangan Sukoharjo, the mother don ' $t$ do gymnastics parturition TFU the 3rd is two cm below the umbilical's mother. Where as she who do gymnastics parturition, the $3 \mathrm{rd}$ TFU $2,5 \mathrm{~cm}$ below the umbilical and stomach looked strong and lax.

The aim of this research is to find influence of gymnastic parturition to speed the post partum involution uteri in the village of Gedangan, grogol, Sukoharjo.

This is a research Methods. The respondent are the post partum in the village of Gedangan Sukoharjo by design the experimental quasy with randomized posttest only control to comparing the puerperium gymnastic exercise between groups given treatment and the puerperium not given treatment gymnastics parturition. Which have collected data and analysis by the independent $\mathrm{t}$-test with $\mathrm{p}=0.05$.

Research results in respondents who do gymnastics parturition obtained $60 \%$ of respondents experienced a decline with TFU range $6.1-8.0 \mathrm{~cm}$ and $40 \%$ in the range of $4.0-6.0$. While the respondents are not done gymnastics parturition decreased TFU all respondents (100\%) are in the range of $4.0-6.0$ $\mathrm{cm}$. from the independent t-test obtained $p$ of 0,000 so $p<0.05$, which means $\mathrm{Ho}$ is rejected and accepted $\mathrm{Ha}$.

The Conclusion of the research was there is influence of gymnastics parturition against the speed of the involution of uteri maternal post partum, in the village of Gedangan Grogol Sukoharjo
\end{abstract}

Keywords: gymnastics parturition, involution uteri, the post partum

\section{PENDAHULUAN}

Salah satu indikator untuk menentukan derajat kesehatan suatu bangsa ditandai dengan tinggi rendahnya angka kematian ibu. Hal ini merupakan suatu fenomena yang mempunyai pengaruh besar terhadap keberhasilan pembangunan kesehatan (Saleha, 2009).
Masa Nifas merupakan hal penting untuk diperhatikan guna menurunkan angka kematian ibu. Dari berbagai pengalaman dalam menanggulangi kematian ibu di banyak negara., para pakar kesehatan menganjurkan upaya pertolongan difokuskan pada masa setelah persalinan. (Saleha, 2009) Setelah persalinan tubuh seorang ibu memasuki masa pemulihan, salah satunya adalah involusi uteri 
yang dimulai segera setelah persalinan dan proses ini harus tuntas setelah 6 minggu. (Brayshaw, 2008)

Involusi uteri adalah suatu proses kembalinya uterus ke keadaan sebelum hamil setelah melahirkan. (Bobak, lowdermilk dan Jensen, 2005) Proses ini merupakan proses klinis yang sangat penting, karena kemungkinan jika proses ini terganggu dapat terjadi pendarahan nifas awitan-lambat.

Untuk mempercepat proses involusi uteri, salah satu latihan yang dianjurkan adalah senam nifas. Senam nifas adalah senam yang dilakukan oleh ibu setelah persalinan, setelah keadaan ibu normal (pulih kembali). Senam nifas merupakan latihan yang tepat untuk memulihkan kondisi tubuh ibu dan keadaan ibu secara fisiologis maupun psikologis. (Maritalia, 2012)

Hasil survey awal yang dilakukan pada ibu post partum di desa Gedangan Grogol Sukoharjo, didapatkan ibu yang tidak melakukan senam nifas, hasil pemeriksaan TFU (Tinggi Fundus Uteri) pada hari ke-3 adalah $2 \mathrm{~cm}$ di bawah pusat, perut ibu tampak "kendor" dan berkurang kekencangan otot perut serta panggul. Sedangkan pada ibu yang melakukan senam nifas setelah persalinan, didapatkan pada hari ke-3 TFU 2,5 cm di bawah pusat serta perut tampak kencang, tidak kendor.

Melihat fenomena di atas, maka peneliti memandang perlu melakukan penelitian tentang "Pengaruh Senam Nifas terhadap Kecepatan Involusi Uteri lbu Post Partum di Desa Gedangan Kecamatan Grogol Kabupaten Sukoharjo".

\section{METODE PENELITIAN}

Pada penelitian ini peneliti menggunakan rancangan penelitian Quasi experimental design dengan pendekatan metode Randomized posttest only control untuk meneliti pengaruh senam nifas terhadap kecepatan involusi uteri ibu post partum di Desa Gedangan Kecamatan Grogol Kabupaten Sukoharjo. Peneliti memberikan perlakuan senam nifas kepada sebagian kelompok, kelompok lainnya tidak diberi perlakukan dan diukur fundus uterinya.

Subyek penelitian adalah 10 ibu post partum di Desa Gedangan Kecamatan Grogol Kabupaten Sukoharjo yang melahirkan pada bulan Januari 2014 dengan tehnik pengambilan sampel secara aksidental, yang memenuhi kriteria inklusi dan eksklusi sebagai berikut : Kriteria inklusi

Ibu post partum hari pertama yang bersedia menjadi responden

Kriteria eksklusi

Ibu post partum yang mengalami komplikasi selama persalinan seperti pendarahan eklamsia

lbu post partum yang menderita kelainan seperti penyakit jantung, ginjal atau diabetes melitus

\section{HASIL PENELITIAN}

Penelitian dilakukan pada 10 ibu post partum hari pertama paska melahirkan. Peneliti melakukan pengukuran TFU terhadap 10 responden pada hari pertama setelah melahirkan. Dari 10 responden tersebut, 5 responden dilakukan senam nifas yang dimulai dalam 24 jam setelah melahirkan dan senam dilakukan setiap hari sampai hari kelima post partum, kemudian dilakukan pengukuran Tinggi Fundus Uteri (TFU). Sedangkan 5 responden lain tidak dilakukan senam nifas dan pada hari kelima post partum dilakukan pengukuran TFU. 
1. Distribusi Frekuensi Penurunan TFU lbu Post Partum yang Dilakukan Senam Nifas

Berdasarkan hasil penelitian didapatkan, dari 5 responden yang dilakukan senam nifas, penurunan TFU yang berada pada rentang $6,1-8,0 \mathrm{~cm}$ ada 3 responden $(60 \%)$ lebih banyak dibandingkan dengan jumlah responden yang mengalami penurunan TFU pada rentang 4,0 - 6,0 cm yaitu 2 responden (40\%), dengan mean (rata-rata) penurunan TFU adalah $6,02 \mathrm{~cm}$ dan median $6,1 \mathrm{~cm}$

2. Distribusi Frekuensi Penurunan TFU Ibu Post Partum Yang Tidak Dilakukan Senam Nifas

Hasil penelitian menunjukkan seluruh responden yang tidak dilakukan senam nifas (100\%) mengalami penurunan TFU pada rentang 4,0 - 6,0 cm, dengan mean (rata-rata) penurunan TFU adalah $4,86 \mathrm{~cm}$ dan median 4,8 $\mathrm{cm}$.

3. Pengaruh Senam Nifas Terhadap Kecepatan Involusi Uteri

Dari hasil uji independent t-test program SPSS versi 18.0 dengan $\alpha=5 \%(0.05)$ diperoleh $p$ sebesar 0,001 sehingga nilai $p<0.05$, yang berarti $\mathrm{Ho}$ ditolak dan $\mathrm{Ha}$ diterima, sehingga ada pengaruh senam nifas terhadap kecepatan involusi uteri ibu post partum di Desa Gedangan Grogol Sukoharjo.

\section{PEMBAHASAN}

Berdasarkan hasil penelitian pengaruh senam nifas terhadap kecepatan involusi uteri dengan jumlah responden sebanyak 10 orang diperoleh gambaran proporsi responden berdasarkan umur adalah pada rentang umur 21 - 25 yang paling banyak yaitu sebanyak $40 \%$.

Penelitian ini merupakan penelitian eksperimen dengan rancangan Randomized posttest only control untuk mengetahui pengaruh senam nifas terhadap kecepatan involusi uteri pada ibu post partum, dengan cara membandingkan pengaruh senam nifas terhadap responden yang dipilih acak, satu kelompok responden diberikan perlakuan senam nifas dengan proporsi perlakuan senam nifas dilakukan satu kali dalam sehari dan satu kelompok lainnya tidak diberikan perlakuan senam nifas lalu diukur dan diamati pada hari kelima setelah melahirkan. Untuk mengetahui adanya pengaruh senam nifas terhadap kecepatan involusi uteri digunakan uji Independent T-test, dengan hasil sebagai berikut:

1. Ibu post partum yang dilakukan senam nifas

Dari penelitian yang dilakukan, didapatkan jumlah responden yang mengalami penurunan tinggi fundus uteri (TFU) dengan rentang 6,1 - 8,0 lebih besar, yaitu 3 responden dengan persentase $60 \%$ dibandingkan dengan responden yang mengalami penurunan tinggi fundus uteri (TFU) dengan rentang 4,0 - 6,0 yaitu 2 responden dengan persentase $40 \%$. Hal ini menunjukkan rata rata penurunan tinggi fundus uteri (TFU) pada 3 responden yang dilakukan senam nifas adalah 1,5 - 2,0 cm setiap harinya.

Penurunan tinggi fundus uteri tersebut terjadi dikarenakan oleh proses involusi uteri. Involusi uteri adalah proses kembalinya uterus ke ukuran semula seperti sebelum hamil. Proses ini dimulai segera setelah plasenta lahir akibat kontraksi otot-otot polos uterus. (Jannah, 2013)

Proses involusi terjadi dapat dipengaruhi oleh beberapa faktor salah satunya yaitu senam nifas. Senam nifas adalah senam yang 
dilakukan oleh para ibu setelah melahirkan dan setelah keadaan tubuhnya pulih kembali. (Anggraini, 2010)

Senam nifas yang dilakukan pada penelitian ini satu kali sehari, senam nifas mulai dilakukan dalam 24 jam setelah persalinan. Sesuai dengan pendapat Maritalia (2012), yang mengatakan senam nifas sebaiknya dilakukan dalam 24 jam setelah persalinan, secara teratur setiap hari. Ibu tidak perlu khawatir terhadap luka yang timbul akibat proses persalinan karena 6 jam setelah persalinan normal dan 8 jam setelah persalinan caesar, ibu sudah dianjurkan untuk melakukan mobilisasi dini. (Maritalia , 2012)

2. Ibu Post Partum yang Tidak Dilakukan Senam Nifas

Dari penelitian yang dilakukan, didapatkan seluruh responden mengalami penurunan tinggi fundus uteri (TFU) dengan rentang $4,0-6,0$ yaitu 5 responden dengan persentase $100 \%$.

Menurut Anggraini (2010) segera setelah persalinan, TFU $2 \mathrm{~cm}$ di bawah pusat, 12 jam kemudian kembali $1 \mathrm{~cm}$ di atas pusat dan menurun kira-kira $1 \mathrm{~cm}$ setiap hari dan pada hari ke dua setelah persalinan TFU $1 \mathrm{~cm}$ dibawah pusat. Pada hari ke 3-4 TFU $2 \mathrm{~cm}$ di bawah pusat. Pada hari ke 5-7 TFU setengah antara pusat dengan sympisis.

Beberapa faktor yang ditemukan peneliti yang mempengaruhi proses involusi selain senam nifas yaitu imobilisasi dini dan menyusui dini. Imobilisasi dini adalah beberapa jam setelah melahirkan, segera bangun dari tempat tidur dan bergerak, agar lebih kuat dan lebih baik. Sedangkan menyusui dini merupakan salah satu faktor pendukung terjadinya proses involusi uteri karena dengan memberikan Air Susu Ibu kepada bayi segera setelah melahirkan sampai satu jam pertama, memberikan efek kontraksi pada otot polos uterus. Oleh karena itu ibu post partum yang tidak dilakukan senam nifas tetap akan mengalami penurunan tinggi fundus uteri (TFU).

Demikian juga responden penelitian yang tidak dilakukan senam nifas mengalami penurunan tinggi fundus uteri tetapi penurunan tinggi fundus uteri hanya sekitar $1,0-1,5 \mathrm{~cm}$ setiap harinya.

3. Pengaruh Senam Nifas Terhadap Kecepatan Involusi Uteri Ibu Post Partum

Berdasarkan analisa bivariat pengaruh senam nifas terhadap kecepatan involusi uteri ibu post partum didapatkan hasil bahwa ada pengaruh senam nifas terhadap kecepatan involusi uteri pada ibu post partum di Desa Gedangan Grogol Sukoharjo. Hal ini ditunjukkan dengan hasil uji statistik 0,000 (probabilitas < 0,05 ) sehingga Ha diterima.

Dalam penelitian ini, senam nifas yang dilakukan oleh responden mempunyai pengaruh yang signifikan terhadap penurunan TFU, dengan kisaran penurunannya $1,5-2,0 \mathrm{~cm}$ setiap hari. Sedangkan pada responden yang tidak dilakukan senam nifas hanya mengalami penurunan TFU dengan kisaran $1,0-1,5 \mathrm{~cm}$ setiap harinya.

Sesuai dengan pernyataan yang disampaikan Brayshaw (2008), yaitu senam nifas adalah senam yang dilakukan ibu setelah 
melahirkan yang bertujuan untuk mempertahankan dan meningkatkan sirkulasi ibu pada masa nifas, serta membantu proses involusi uteri.

Menurut analisa peneliti yang sesuai dengan pendapat dari Roito, Noor, dan Mardiah (2011), yaitu penurunan TFU yang dialami oleh responden yang dilakukan senam nifas dikarenakan dalam prosedur senam nifas terdapat gerakan senam yang bertujuan untuk mempercepat pengembalian uterus pada bentuk dan posisi semula seperti sebelum hamil.

Hasil penelitian yang peneliti dapatkan sama dengan dua penelitian terdahulu, yaitu penelitian yang dilakukan oleh Trimarwati (2009) yang mendapatkan hasil bahwa senam nifas mempunyai pengaruh yang bermakna terhadap involusi uterus pada hari I-III post partum di RSKIA PKU Muhammadiyah Kota Gede dan penelitian yang dilakukan oleh Surani (2010), yang mendapatkan hasil bahwa sebagian besar responden yang diberi perlakuan senam nifas, mengalami penurunan TFU cepat yaitu sebanyak 38 orang $(76 \%)$, dan yang mengalami penurunan TFU lambat 12 orang (24\%).

\section{KESIMPULAN DAN SARAN}

Dari hasil penelitian, peneliti dapat mengambil kesimpulan sebagai berikut :

Rata - rata penurunan TFU pada responden yang dilakukan senam nifas adalah 1,0 - 2,0 cm setiap harinya. Sedangkan pada responden yang tidak dilakukan senam nifas rata - rata penurunan TFU adalah 1,0 - 1,5 $\mathrm{cm}$ setiap harinya.
Ada pengaruh senam nifas terhadap kecepatan involusi uteri ibu post partum di Desa Gedangan Grogol Sukoharjo. Hal ini ditunjukkan dengan hasil uji statistik $\mathrm{p}=0,000$ (probabilitas < 0,05 ) sehingga Ha diterima

\section{Saran}

1. Bagi Masyarakat

Disarankan kepada ibu post partum agar melakukan senam nifas setelah persalinan

2. Bagi Institusi Pendidikan Keperawatan

Pembelajaran senam nifas perlu tetap disampaikan dalam salah satu materi perkuliahan pada mata ajar keperawatan maternitas.

3. Bagi Instansi Pelayanan Kesehatan

Disarankan untuk mengajarkan senam nifas kepada ibu post partum dan memberi motivasi pada ibu untuk tetap melakukan senam nifas secara rutin setelah pulang dari rumah sakit atau tempat bersalin lainnya.

4. Bagi Peneliti Selanjutnya

Hasil penelitian ini diharapkan dapat digunakan sebagai dasar untuk penelitian selanjutnya yang berhubungan dengan senam nifas dengan jumlah sampel yang lebih besar agar diperoleh hasil penelitian yang lebih baik.

\section{KEPUSTAKAAN}

Anggraini, Yetti. Asuhan Kebidanan Masa Nifas. Yogyakarta: Pustaka Rihama, 2010.

Brayshaw, Eileen. Senam Hamil dan Nifas : Pedoman Praktik Kedokteran. Alih bahasa 
“KOSAเn” JIK. Vol. 2 No. 1 Maret 2014

Ramona P. Kapoh. Jakarta: EGC, 2008.

Bobak, Irene M, Deitra Leonard Lowdermilk dan Margaret Duncan Jensen. Buku Ajar Keperawatan Maternitas. Alih bahasa Maria A. Wijayarini dan Peter I. Anugerah. Jakarta: EGC, 2005.

Jannah, Nurul. Asuhan Kebidanan Ibu Nifas. Yogjakarta: Ar-Ruzz Media, 2013.
Maritalia, Dewi. Asuhan Kebidanan Nifas dan Menyusui. Yogyakarta: Pustaka Pelajar, 2012.

Roito, H. Juraida, Nurmailis Noor, dan Mardiah. Asuhan Kebidanan Ibu Nifas: Penuntun Belajar Praktik Klinik. Jakarta: EGC. 2010

Saleha, Siti. Asuhan Kebidanan Pada Masa Nifas. Jakarta: Salemba Medika, 2009.

Dosen AKPER Panti Kosala Surakarta

2 Dosen AKPER Panti Kosala Surakarta

3 Mahasiswa AKPER Panti Kosala Surakarta 